\title{
Trabalhando a ideia de fração na cultura da antiga civilização egípcia
}

\author{
Edmar Luiz Gomes Júnior \\ Instituto Federal de Minas Gerais - Campus Ouro Preto \\ edmarlgj@hotmail.com
}

\section{Davidson Paulo de Oliveira Azevedo}

Instituto Federal de Minas Gerais - Campus Ouro Preto

davidson.oliveira@ifmg.edu.br

\begin{abstract}
Resumo
A tarefa apresentada a seguir foi elaborada originalmente para ser trabalhada com alunos do $6^{\circ}$ ano do Ensino Fundamental, adaptando uma situação da antiga civilização egípcia que trabalhava geralmente com frações unitárias, no intuito de promover um ambiente possivelmente capaz de estimular os alunos a analisar e discutir sobre a ideia inicial de frações, tratando-se assim de uma sugestão para a sala de aula.
\end{abstract}

Palavras-chave: História da Matemática. Frações. Frações Egípcias. Ensino Fundamental.

\section{Working the fractions idea in the ancient Egyptian civilization culture}

\begin{abstract}
The task presented below was originally designed to be worked with students from the 6th grade of midlle school, adapting a situation of the ancient Egyptian civilization who worked often with unit fractions, in order to promote a possibly enabling environment to encourage students to analyze and discuss the initial idea of fractions, therefore, it is a suggestion for the classroom.
\end{abstract}

Keywords: History of Mathematics. Fractions. Egyptian fractions. Elementary School.

\section{Introdução}

Um dos argumentos para o uso da História da Matemática em sala de aula levantado por Miguel (1997) é a possibilidade de promover uma aprendizagem significativa e compreensiva.

Além disso, a ordem na qual os conceitos e noções da Matemática foram construídos ao longo da História põe em evidência os obstáculos encontrados durante esse desenvolvimento. A recriação teórica desse processo em sala de aula, adaptado, evidenciaria o sentido e os limites da 
Matemática, salientando que a História deveria delinear e estruturar a exposição dos conceitos matemáticos, mas não de forma mecânica (Zuniga, 1988 citado por Miguel, 1997).

Assim, em relação ao ensino de frações, lembramos que os egípcios só trabalhavam com frações unitárias ou partes (frações com numerador 1), com a exceção de $\frac{2}{3}$, talvez porque estas frações sejam mais naturais, ou seja, intuitivas (KATZ, 2008).

É nesse sentido também que Bertoni (2005) destaca a importância de trabalhar com frações unitárias em sala de aula, uma vez que:

[...] um conhecimento mais consistente das frações unitárias em si mesmas é importante para garantir a construção das frações gerais pelos alunos, com compreensão. $\mathrm{O}$ entendimento das frações unitárias envolve vários conhecimentos básicos para a construção conceitual do número fracionário, que devem ser explorados em sala de aula. (BERTONI, 2005, p.14)

Tendo em vista que a antiga civilização egípcia já trabalhava com números fracionários em seu aspecto mais básico e principalmente usual, a tarefa proposta tem como objetivo reproduzir uma situação rotineira do Antigo Egito, adaptada aos dias atuais, usando como instrumento de medida um "pedaço de corda com nós” com o intuito de proporcionar um ensino e uma aprendizagem naturais e intuitivos do conceito de fração.

\section{Tarefa proposta}

Para esta tarefa necessitaremos de um espaço extra-classe maior, como o pátio ou a quadra da escola, giz para demarcar os "terrenos antes inundados pelo Nilo" e uma corda pré-delimitada com nós (por exemplo de $10 \mathrm{~cm}$ em $10 \mathrm{~cm}$ ).

$\mathrm{Na}$ área escolhida para realização da atividade sugerimos que o professor demarque uma área retangular que será tida como o terreno a ser repartido novamente após a cheia do rio Nilo. Em seguida, o professor seleciona os alunos que serão os "agricultores" que tiveram seus terrenos invadidos durante a cheia do rio Nilo e aqueles que serão os "esticadores de corda" (agrimensores), que são funcionários do Faraó e que medem o terreno através de nós em cordas.

Cada agricultor irá se reunir com seus estiradores de corda e lhes dizer "quantos nós" acredita que seriam necessários para delimitar suas terras. Será pensada em uma demarcação horizontal e não levada em consideração a área, visto que, o intuito da atividade é fornecer números fracionários como consequência. No entanto, se algum aluno questionar sobre as áreas, aproveite para discutir com eles esse conceito.

Em seguida vai o primeiro esticador de corda e demarca a terra do primeiro agricultor, e assim por diante. É preciso estimular os alunos agricultores a solicitarem uma maior quantidade de 
nós de modo que não sobre terra a ser dividida para os últimos agricultores, surgindo assim um primeiro problema como o do exemplo a seguir.

Quadro 1 - Exemplo de um possível problema

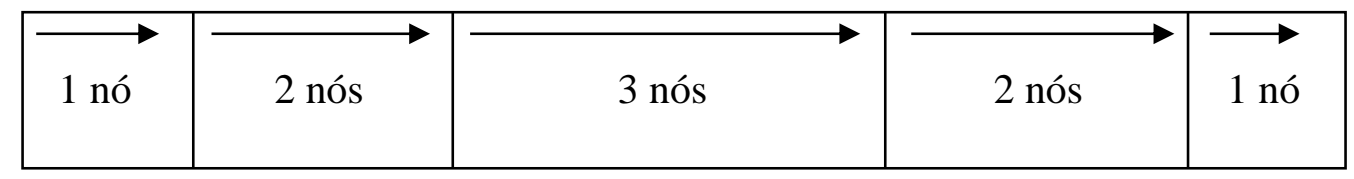

Fonte: Dados da pesquisa.

Problema: Faltaria ainda demarcar o terreno de 15 agricultores.

Diante disso, o professor pode ter em mãos um papiro com um decreto do Faraó no qual solicita que a terra invadida pelo rio Nilo seja dividida igualmente entre os agricultores. Toda a demarcação anterior será desfeita e todos os alunos, esticadores de corda e agricultores, serão reunidos e discutirão o problema (mais detalhes podem ser vistos na atividade).

É necessário pensar na quantidade demarcada para medição (área riscada pelo professor) como uma quantidade de números naturais de nós que, quando dividida pela quantidade de alunos agricultores, resulte em números decimais que não sejam dizimas periódicas. É importante também que a atividade seja direcionada, de modo que os alunos façam a divisão do número de cordas total (número natural) e percebam o resto, com o qual deverão trabalhar e discutir quantas das partes daquele resto ficará para cada agricultor.

Sugerimos, ainda, que o professor inicie uma discussão quanto à representação ser referente ao inteiro ou a uma quantidade, isto quando o resto da divisão do terreno pelo número de alunos for maior que 1, o que não é o ideal, visto que é uma atividade de introdução e os alunos possivelmente não estarão familiarizados com os números decimais, apesar de eles provavelmente já terem estudado nas séries iniciais. Por isso a importância de se demarcar a área pensando na quantidade de alunos e, quando possível, em um resto 1 para essa divisão.

Discutido isto, o professor deve apresentar aos alunos o método pelo qual os egípcios escreviam as frações e cada esticador de corda registrará em sua atividade a demarcação dos terrenos de cada agricultor.

É necessário que haja ainda outro momento entre os estudantes, para que eles possam discutir os resultados finais encontrados por cada dupla (esticador e agricultor). Seria interessante que, nesta fase, os alunos percebessem que uma prova possível da validade dos resultados encontrados seria a soma de cada um deles, que, caso estejam corretos, resultará na medida total da área demarcada anteriormente pelo professor.

Levando em consideração que os estudantes possivelmente não tenham trabalhado ainda com os métodos formais de soma de frações, tais operações devem ser feitas intuitivamente, não 
sendo exigida esta formalidade (é possível que já tenham trabalhado com operações com frações no terceiro ano). Outra questão é quanto à forma de validação utilizada pelos estudantes que deve ser avaliada pelo professor, não sendo necessariamente a soma das medidas individuais resultando na medida total.

A seguir, seria interessante um retorno à sala de aula (se a atividade ocorrer em outro local), onde o professor deve retomar para ele a responsabilidade concedida ao aluno dando o status de saber e descartando produções dos alunos que não estejam de acordo com o proposto além de explicitar o conceito de fração formalizando e generalizando.

\section{Quadro 2 - Trabalhando com o conceito de fração (Tarefa do aluno)}

\section{Tarefa: Trabalhando com o conceito de fração}

A seguir temos um fragmento do texto do historiador grego Heródoto que nos diz um pouco sobre a medição dos antigos egípcios por cordas:

"Quando o Nilo transborda, cobre o Delta e as terras chamadas Líbia e Arábia, numa distância de uma viagem de dois dias desde as duas margens, não consegui saber nada da sua natureza, nem dos sacerdotes nem de qualquer outra pessoa. Tinha curiosidade em saber por que é que o rio transborda durante cem dias desde o solstício de Verão... e o rio está baixo durante todo o Inverno até transbordar de novo no solstício de Verão.

Por esta razão o Egito foi dividido. Disseram-me que este rei (Sesóstris) repartiu todo o país entre os egípcios, dando a cada um uma porção igual de terra, e fê-lo sua fonte de rendimento, avaliando o pagamento de um tributo anual. E se qualquer homem que fosse roubado pelo Nilo de uma porção de suas terras podia dirigir-se a Sesóstris e expor a ocorrência, então o rei enviaria um homem para verificar e calcular e parte pela qual a terra tinha sido reduzida, de tal forma que a partir dessa altura ele deveria pagar proporcionalmente ao tributo imposto originalmente.

Esta foi a forma como, em minha opinião, os Gregos aprenderam a arte de medir a terra; os relógios de sol, os gnomos e as doze divisões do dia, vêm para a Grécia da Babilónia e não do Egito."

Heródoto (II, 109)

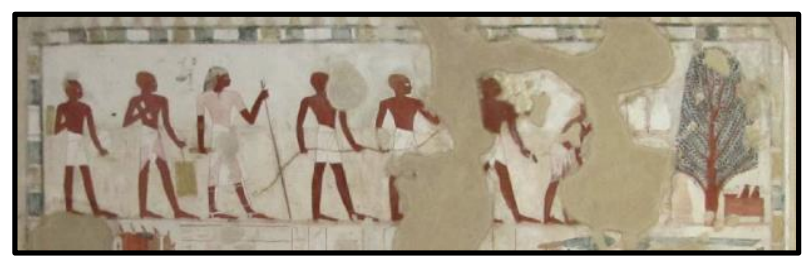

Esticadores de cordas, túmulo de Djeserkareseneb - (OsirisNet, 2010)

Se você foi escolhido como agricultor, irá se reunir com um esticador de corda e lhe dizer "quantos nós" acredita que delimitam suas terras. Se você foi escolhido como esticador de corda, deve junto com os demais esticadores estabelecer uma ordem e iniciar as demarcações de terra de cada agricultor, um por um, sabendo que uma mesma parte do terreno não pode pertencer a mais de um agricultor.

Houve algum problema? 
Se sim, continue.

Diante do problema encontrado, houve um decreto do Faraó no qual ele solicita que a terra alagada pelo rio Nilo seja dividida igualmente entre todos os agricultores. Desfaçam toda a demarcação anterior, reúna-se com seu colega (agricultor e esticador de corda responsáveis um pelo outro) e discutam o novo problema.

\section{Registro}

Registre aqui como representariam a parte do terreno de cada um de dois modos diferentes sendo um deles, necessariamente, o modo como os egípcios faziam.

\section{Para discutir}

Discutam com as demais duplas os resultados encontrados por cada um. Tente convencer os colegas, caso os resultados não sejam os mesmos, usando argumentos matemáticos.

Fonte: Produzido pelos autores.

O professor poderá utilizar aproximadamente duas aulas de 50 minutos para desenvolver essa tarefa. Sugerimos a possibilidade de não apresentar aos alunos nenhum detalhamento ou explicação sobre o tema, ou seja, realizar o mínimo de intervenção possível.

\section{Considerações finais}

Ao propor estas tarefas para a sala de aula, acreditamos que podemos promover uma discussão entre os diferentes modos de pensar dos alunos. Caso se utilize a tarefa como exercício rotineiro, resolvido pelo professor na lousa, toda a potencialidade da tarefa ficará comprometida e os objetivos para os quais foram criadas - por exemplo, estimular o debate de ideias natural e intuitivo de fração - ficarão prejudicados. Pensamos que o aluno, por sua vez, deva ser orientado a mudar sua postura de buscar respostas prontas, únicas, baseadas na cultura do "certo" e do "errado" do ensino tradicional.

É importante observar que essa tarefa também têm como objetivo exercitar a leitura e interpretação dos estudantes e, como consequência, estimulá-los a falar sobre o que entenderam daquilo que foi apresentado além de apresentar ideias que julgamos importantes inicialmente acerca do conteúdo de frações. Possivelmente, o caráter da tarefa pode propiciar um aprendizado com um significado para o estudante, um dos objetivos de se utilizar a História da Matemática no ensino.

\section{Referências}

BERTONI, N. E. Número fracionário: primórdios esclarecedores. Rio Claro: SBHMat, História da Matemática para Professores. 2005.

HERODOTUS. Histories. Ed. A.D. Godley, Vol I. LCL. New York: G.P. Putnam's Son; London: Heinemann, 1920. 
HIRST, J. J In BEBDERITTER, T. The Osirisnet Project. Switzerland. 2010. Disponível em: <http://www.osirisnet.net/tombes/nobles/djeserkareseneb38/e_djeserkareseneb_03.htm>. Acesso em: 16 mar. 2016.

KATZ, V. J. A history of mathematics. New York, Addison Wesley, 3.ed., 2008.

MIGUEL, A. As potencialidades pedagógicas da História da Matemática em questão:argumentos reforçadores e questionadores. Zetetiké. v.5, n.8, p.73-115. 1997.

ROBINS, G.; SHUTE, C. The Rhind mathematical papyrus: an ancient Egyptian text.

Michigan. British Museum Publications. 1987.

Submetido em abril de 2016

Aprovado em junho de 2016 